\title{
Hubungan Iklim Keselamatan Dengan Budaya K3 Di Proyek Citra Tower Kemayoran
}

\author{
Evi Nopiyanti, Akhmad Muttaqin \\ Program Studi Kesehatan Masyarakat, Fakultas IImu Kesehatan, Universitas Respati Indonesia \\ Jl. Bambu Apus 1 No.3, Cipayung, Jakarta Timur, 13890 \\ Email: evinopiyanti972@gmail.com
}

\begin{abstract}
ABSTRAK
Keselamatan dan kesehatan kerja (K3) di Proyek Citra Tower Kemayoran, belum sepenuhnya menjadi nilai-nilai dan kepercayaan yang berhubungan dengan setiap aktivitas tugas yang dikerjakan, sehingga mempengaruhi perilaku pekerja dalam melaksanakan pekerjaan yang berakibat pada kejadian kecelakaan yang berulang-ulang. Tujuan penelitian ini adalah ingin mengetahui hubungan iklim keselamatan dengan budaya K3 pada Proyek Citra Tower Kemayoran. Penelitian dilaksanakan tanggal 16 Agustus-22 November 2019. Jenis penelitian menggunakan mixed method, yaitu metode yang memadukan pendekatan kualitatif dan kuantitatif. Metode pengumpulan data menggunakan survei, observasi, wawancara, FGD, dan kaji dokumentasi. Data dianalisis dengan teknik likert dan cross sectional. Hasil penelitian menunjukkan tingkat iklim keselamatan di Proyek Citra Tower mendapat nilai 2,02-3,07, artinya termasuk katagori cukup baik; tingkat budaya K3 mendapatkan total nilai 671 artinya termasuk katagori Baik; dan 7 dimensi iklim keselamatan tidak berhubungan dengan budaya K3 dengan nilai $p$ value dimensi $1(0,932)$; dimensi $2(0,844)$; dimensi $3(1,000)$; dimensi 4 $(0,87)$; dimensi 5 (1,000); dimensi $6(1,000)$; dan dimensi $7(0,831)$. Disarankan manajemen meningkatkan komitmen, kompetensi, konsultasi, dan partisipasi semua pihak.
\end{abstract}

Kata kunci : Safety climate, safety culture, proyek.

\begin{abstract}
Occupational safety and health (K3) in the Citra Tower Kemayoran Project, have not fully become the values and beliefs associated with each task activity undertaken, thus affecting the behavior of workers in carrying out work that results in repeated accidents. The purpose of this study was to determine the relationship of safety climate with K3 culture in the Citra Tower Kemayoran Project. The study was conducted on August 16-November 222019. This type of research uses a mixed method, which is a method that combines qualitative and quantitative approaches. Data collection methods use surveys, observations, interviews, FGDs, and review documentation. Data were analyzed by likert and cross sectional techniques. The results showed the level of safety climate in the Citra Tower Project received a score of 2.023.07 , which means that the category is quite good; the level of $\mathrm{K} 3$ culture gets a total value of 671 which means it belongs to the Good category; and 7 dimensions of safety climate are not related to K3 culture with $\mathrm{p}$ value of dimension 1 (0.932); dimension $2(0.844)$; dimension 3 $(1,000)$; dimension 4 (0.87); dimension $5(1,000)$; dimension $6(1,000)$; and dimension 7 (0.831). It is recommended that management increase the commitment, competence, consultation, and participation of all parties.
\end{abstract}

Keywords: Safety climate, safety culture, project.

http://ejournal.urindo.ac.id/index.php/kesehatan

Article History :

Sumbitted 18 Mei 2020, Accepted 29 Juni 2020, Published 30 Juni 2020 


\section{PENDAHULUAN}

Proyek konstruksi merupakan salah satu industri yang rawan terhadap kecelakaan. Angka kecelakaan kerja yang cukup tinggi pada proyek konstruksi menyebabkan kerugian yang sangat besar. Angka kecelakaan kerja terus menunjukkan tren meningkat. Badan Penyelenggara Jaminan Sosial (BPJS) Ketenagakerjaan mencatat, pada tahun 2017 angka kecelakaan kerja yang dilaporkan mencapai 123.041 kasus, sementara sepanjang 2018 mencapai 173.105 kasus dengan klaim Jaminan Kecelakaan Kerja (JKK) sebesar Rp 1,2 triliun (Widianto, 2019). Khusus Jakarta terjadi peningkatan angka kecelakaan kerja hingga 10 \% pada tahun $2017 \quad$ (Prins, 2018). Bisnis.com mencatat bahwa sejak Agustus 2017-2018, sedikitnya 14 kecelakaan konstruksi telah terjadi. Artinya, rata-rata sekitar dua kali kejadian dalam sebulan (Mola, 2018). Total korban meninggal dunia sebanyak 9 orang dan 16 orang mengalami cedera berat maupun luka ringan. Kerugian itu belum termasuk kerugian materill dan imateriil, serta belum termasuk kecelakaan yang tidak tercatat (Supriyadi, 2018).

Maulia (2018) menyebutkan
bahwa kecelakaan kerja konstruksi
disebabkan oleh pelaksanaan proyek yang

"fast and furious". Selain itu, kurang disiplinnya (perilaku) tenaga kerja dalam mematuhi K3, masih lemahnya komitmen dan pengawasan K3 di internal tempat kerja, tidak optimal penerapan K3, serta masih lemahnya iklim keselamatan dan budaya K3 (Dhakiri, 2018). Sedangkan menurut Kementerian PUPR, Indonesia masih kekurangan tenaga ahli konstruksi (Yasmin, 2018). Tingkat kelalaian sumber daya manusia (SDM) serta tidak dipatuhinya prosedur operasi standar (SOP) masih tinggi (Dirjen Bina Marga Kemen PUPR, 2018).

Menurut Reason (1997) program K3 sebaiknya dimulai dari tahap yang paling dasar, yaitu pembentukan budaya K3. Komitmen dan keterlibatan manajemen puncak (top management) merupakan hal yang paling mendasar dan paling penting dalam menggerakkan partisipasi pekerja terhadap pemenuhan perilaku kerja aman untuk mencapai budaya K3 unggul (Somad, 2013). Berdasarkan beberapa penelitian, bahwa budaya K3 dapat terbentuk dari, komitmen top management, peraturan dan prosedur K3, komunikasi, kompetensi pekerja, keterlibatan pekerja, dan lingkungan kerja (Christina, 2012). Dalam penerapan budaya K3 (safety culture) diperlukan juga safety climate (iklim keselamatan kerja). Wiegman (2002) mengatakan bahwa safety 
climate adalah ukuran safety culture sesuai dengan kesamaan persepsi antara individu dalam organisasi. Safety climate dapat dianggap sebagai fitur permukaan dari safety culture (Flin, 2000). Safety culture adalah produk yang dihasilkan dari individu, kelompok, sikap, persepsi, dan juga pola perilaku yang menentukan komitmen dan kecakapan dalam menata organisasi keselamatan menurut International Atomic Energy Agency-IAEA (1991).

Menurut Cooper (2002) safety culture adalah usaha yang dapat di observasi dimana semua anggota organisasi mengarahkan perhatian dan tindakan mereka terhadap peningkatan keselamatan setiap hari. Dalam safety culture terdapat tiga aspek utama, yaitu person, job, dan organization yang dapat diukur baik dengan pendekatan kualitatif maupun kuantitatif. Hal itu menunjukkan bahwa safety culture harus dilaksanakan oleh seluruh sumber daya yang ada, pada seluruh tingkatan dan tidak hanya berlaku untuk pekerja saja. Para ahli keselamatan menggunakan safety climate untuk memahami safety culture melalui sikap dan perilaku anggota dalam penerapan manajemen keselamatan dan lingkungan kerja (Flin, 2000 dan Guldenmund, 2000). Oleh karena itu, safety climate merupakan ciri serta indikator yang penting dari safety culture dalam organisasi. Konsep word class safety culture yang diajukan oleh Reach Group (1984) juga merujuk pada pentingnya behavior based safety (BBS), serta sistem manajemen keselamatan dalam menurunkan tingkat kecelakaan pada industri.

Hasil penelitian yang telah dilakukan

oleh Neal et al (2000) dan Amponsah-

Tawaih (2016) menunjukkan bahwa iklim keselamatan kerja (safety climate) dapat digunakan untuk memprediksi perilaku aman dalam bekerja (safety behavior). Reason mengungkapkan bahwa budaya keselamatan kerja yang baik dapat membentuk perilaku pekerja terhadap keselamatan kerja yang diwujudkan melalui perilaku aman dalam melakukan pekerjaan. Pada penelitian Glendon dan Litherland (2001), bahwa safety climate atau safety culture mempengaruhi performansi keselamatan secara aktual. Gershon et al (2000) menyatakan bahwa saat safety culture menguat, maka akan mengakibatkan performansi keselamatan. Hasil penelitian yang telah dilakukan dalam berbagai perusahaan di beberapa bidang oleh Neal, Griffin dan Hart (2000), Pacquet (2013), Huang et al (2014), dan Jebb (2015) menunjukkan bahwa, ada keterkaitan yang erat antara safety behavior dengan safety 


\section{Jurnal Bidang IImu Kesehatan}

climate. Begitu pun penelitian yang dilakukan oleh Taqwa (2017), diperoleh nilai koefisien penelitian sebesar 0,110 artinya bahwa safety climate memberikan sumbangan efektif sebesar $11 \%$ terhadap safety behavior.

PT Jagat Interindo melaksanakan pekerjaan curtain wall facade di proyek Citra Tower Kemayoran. Keselamatan dan kesehatan kerja (K3) di Proyek Citra Tower Kemayoran, belum sepenuhnya menjadi nilai-nilai dan kepercayaan bersama (manajemen dan pekerja) yang berhubungan dengan setiap aktivitas tugas yang dikerjakan, sehingga mempengaruhi perilaku pekerja dalam melaksanakan pekerjaan yang berakibat pada kejadian kecelakaan yang berulang-ulang. Berdasarkan dokumen leading indicator pada proyek Citra Tower Kemayoran belum tercapai dengan sempurna dikarenakan masih banyak program $\mathrm{K} 3$ yang belum terlaksana pada pembangunan proyek, serta masih terjadi kecelakaan kerja yang menyebabkan kerugian pada pekerja dan perusahaan. Selain itu, PT Jagat Interindo belum pernah dilakukan penilaian analisis kematangan budaya. Berdasarkan latar belakang tersebut, maka penulis tertarik meneliti tentang hubungan iklim keselamatan dengan budaya $k 3$ di perusahaan konstruksi tersebut.

\section{METODE PENELITIAN}

Jenis penelitian ini mix-method penelitian, yaitu metode yang memadukan pendekatan kualitatif dan kuantitatif. Strategi pengumpulan data iklim keselamatan adalah observasi dan wawancara, sedangkan untuk budaya keselamatan dengan observasi, survei, wawancara, studi dokumentasi, dan Focus Group Discussion (FGD). Data yang didapat dianalisis secara kualitatif dan kuantitatif dengan penilaian likert dan cross sectional. Penelitian ini dilakukan di Proyek Citra Tower Kemayoran, pada tanggal16 Agustus - 22 November 2019. Sampel dalam penelitian ini sama dengan populasi, yaitu seluruh pekerja konstruksi di Proyek Citra Tower Kemayoran, berjumlah 59 orang.

Data penelitian yang sudah didapat dari kuesioner NOSACQ-50 (Kines, 2011) dianalisis dengan menggunakan skala likert. Penilaian skala likert NOSACQ-50 dapat dilihat pada tabel 1 di bawah ini: 
Tabel 1. Penilaian Skala Likert NOSACQ-50

\begin{tabular}{lclc}
\hline \multicolumn{1}{c}{ Pertanyaan Positif } & \multicolumn{2}{c}{ Pertanyaan Negatif } \\
\multicolumn{1}{c}{ Kriteria } & Nilai & \multicolumn{1}{c}{ Kriteria } & Nilai \\
\hline Sangat setuju & 4 & Sangat setuju & 1 \\
Setuju & 3 & Setuju & 2 \\
Tidak setuju & 2 & Tidak setuju & 3 \\
Sangat tidak setuju & 1 & Sangat tidak setuju & 4 \\
\hline
\end{tabular}

Hasil penelitian tingkat persepsi standar NOSACQ-50 dapat dilihat pada tabel 2 di bawah ini :

Tabel 2. Tingkat Persepsi Setiap Dimensi NOSACQ-50

\begin{tabular}{cc}
\hline Skor Mean & Hasil \\
\hline$>3,30$ & Baik \\
$3,00-3,30$ & Cukup baik \\
$2,70-2,99$ & Cukup rendah \\
$<2,70$ & Sangat rendah \\
\hline
\end{tabular}

Penilaian diri mengenai budaya keselamatan dengan menggunakan 5 skala likert, yaitu sebagai berikut :

Tabel 3. Penilaian Skala Likert Penilaian Diri Budaya Keselamatan

\begin{tabular}{lcc}
\hline & Kriteria & Nilai \\
\hline Sangat baik & 5 \\
Baik & 4 \\
cukup & 3 \\
Kurang & 2 \\
Buruk & 1 \\
\hline
\end{tabular}

Cara perhitungan untuk mendapatkan jumlah skor penilaian diri budaya keselamatan :

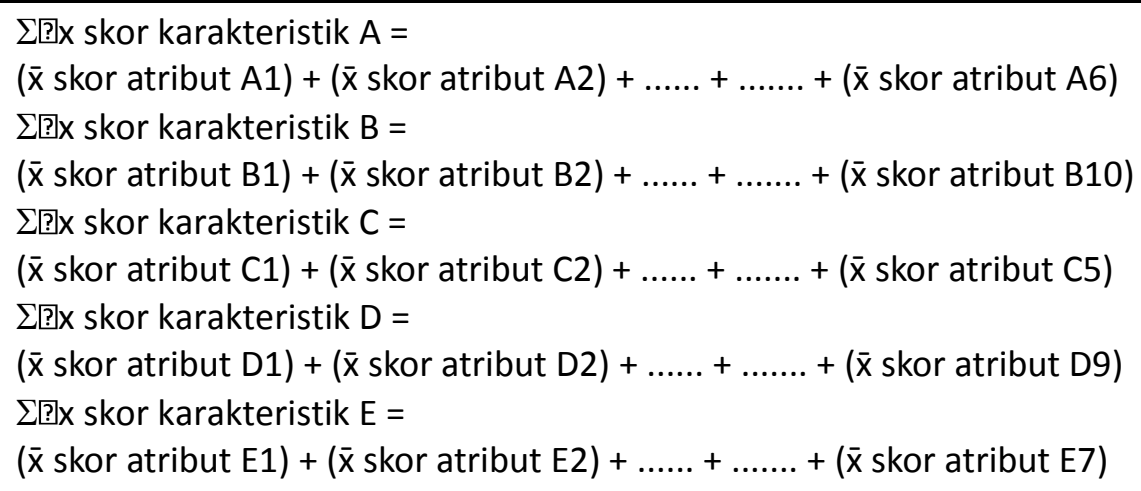

Skor budaya keselamatan $=$ 
$\left(\sum \bar{x}\right.$ skor karakteristik $\left.A\right)+\left(\sum \bar{x}\right.$ skor karakteristik $\left.B\right)+\left(\sum \bar{x}\right.$ skor karakteristik $\left.C\right)+\left(\sum \bar{x}\right.$ skor karakteristik $\mathrm{D})+\left(\sum \overline{\mathrm{x}}\right.$ skor karakteristik $\left.\mathrm{E}\right)$

Klasifikasi pemeringkatan budaya Assessment Review Team (2008) dapat
keselamatan sesuai SCART Guideline dilihat pada tabel 4 di bawah ini :

Reference Report for IAEA Safety Culture

Tabel 4. Skor Pemeringkatan Budaya Keselamatan

\begin{tabular}{|c|c|c|c|}
\hline Peringkat & Skor & Hasil & Keterangan \\
\hline A & $834-1000$ & Sangat Baik & $\begin{array}{l}\text { Kinerja keselamatan di atas ketentuan yang } \\
\text { disyaratkan, sehingga tidak menyebabkan } \\
\text { terhadap kepatuhan persyaratan keselamatan. }\end{array}$ \\
\hline B & $667-833$ & Baik & $\begin{array}{l}\text { Kinerja keselamatan sesuai dengan ketentuan yang } \\
\text { disyaratkan dan tidak menyebabkan risiko terhadap } \\
\text { kepatuhan persyaratan keselamatan. }\end{array}$ \\
\hline C & $534-666$ & Cukup & $\begin{array}{l}\text { Kinerja keselamatan di bawah ketentuan yang } \\
\text { disyaratkan dan akan menyebabkan risiko terhadap } \\
\text { kepatuhan persyaratan keselamatan. }\end{array}$ \\
\hline D & $400-533$ & Kurang & $\begin{array}{l}\text { Kinerja keselamatan secara signifikan berada di bawah } \\
\text { yang disyaratkan dan kemungkinan besar akan } \\
\text { menimbulkan tidakefisienan yang berlanjut } \\
\text { menimbulkan risiko kecelakaan. }\end{array}$ \\
\hline$E$ & $0-400$ & Buruk & $\begin{array}{l}\text { Kinerja keselamatan berada dalam ketidakcukupan, } \\
\text { ketidakefisienan, tidak adanya kendali, atau kontrol } \\
\text { terhadap program budava keselamatan. }\end{array}$ \\
\hline
\end{tabular}

HASIL DAN PEMBAHASAN

Iklim Kerja (Safety Climate)

Dari hasil kuesioner NOSACQ-50

mengenai persepsi iklim keselamatan yang

ditanyakan kepada pihak manajemen dan

Tabel 5. Tingkat Persepsi Manajemen dan Pekerja Terhadap Tujuh Dimensi Iklim Keselamatan Di Proyek Citra Tower Kemayoran

\begin{tabular}{llc}
\hline \multicolumn{1}{c}{ Dimensi Iklim Keselamatan } & Mean \\
\hline 1. Prioritas keselamatan kerja manajemen, komitmen dan kompetensi & 3,00 \\
2. Kewenangan keselamatan kerja dari manajemen & 3,00 \\
3. Keadilan terhadap keselamatan kerja dari manajemen & 3,03
\end{tabular}


4. Komitmen keselamatan kerja dari para pekerja $\quad 3,02$

5. Prioritas keselamatan kerja dari pekerja dan sikap tidak mau ambil risiko $\quad 2,02$

6. Komunikasi dan pelatihan keselamatan kerja 3,07

7. Kepercayaan pekerja terhadap sistem keselamatan kerja 3,04

Berdasarkan hasil perhitungan skor ratakeseluruhan dalam bentuk radar chart di rata 7 dimensi iklim keselamatan, maka bawah ini.

dapat digambarkan kondisi iklim

keselamatan Di Proyek Citra Tower secara

Gambar 1. Radar Chart Tingkat Persepsi Manajemen dan Pekerja Terhadap Tujuh Dimensi Iklim Keselamatan Di Proyek Citra Tower Kemayoran

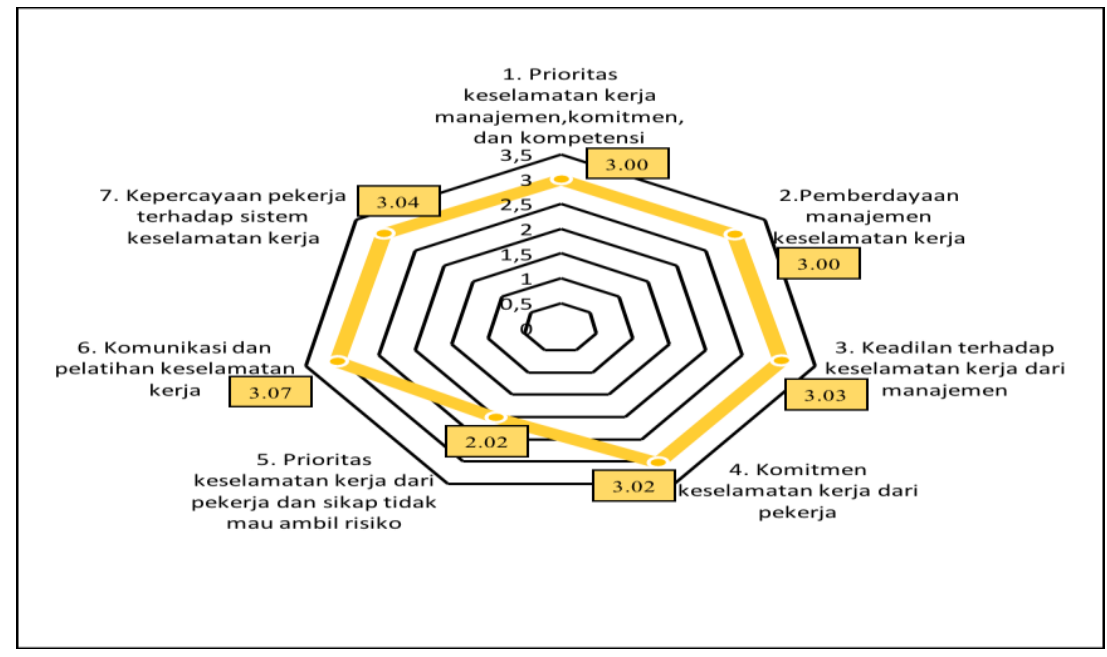

Berdasarkan tabel 5 dan gambar $1 \mathrm{di}$ atas, tingkat persepsi manajemen dan pekerja terhadap 7 dimensi iklim keselamatan didapat hasil nilai dengan skor tertinggi, yaitu 3,07 pada dimensi 6 serta skor terendah, yaitu 2,02 pada dimensi 5 . Secara keseluruhan tingkat persepsi manajemen dan pekerja terhadap iklim keselamatan Di Proyek Citra Tower Kemayoran adalah termasuk katagori cukup baik $(3,00-3,30)$.

http://ejournal.urindo.ac.id/index.php/kesehatan
Dimensi yang memiliki skor tertinggi adalah komunikasi dan pelatihan keselamatan kerja dengan skor 3,07. Sedangkan dimensi yang memiliki skor terendah adalah prioritas keselamatan kerja dari pekerja dan sikap tidak mau ambil risiko dengan skor 2,02. Cigularov et al., (2010) menyatakan bahwa komunikasi yang efektif sangat penting, yaitu untuk terlibat pekerja di kegiatan keselamatan, mempertahankan budaya K3 yang positif, serta untuk mencapai dukungan dan 


\section{Jurnal Bidang IImu Kesehatan}

kerjasama. Rafidah (2014) dari hasil penelitiannya mengatakan komunikasi keselamatan memiliki pengaruh yang signifikan terhadap keselamatan kerja.

Tingginya skor komunikasi dan pelatihan keselamatan kerja di proyek Citra Tower menunjukkan semua personel yang ada dalam perusahaan mendukung implementasi K3 dan sebagai bentuk partisipasi perusahaan dalam sistem manajemen K3. Bentuk komunikasi keselamatan yang dilakukan di proyek, seperti tool box meeting, safety talk, safety sign, HIRADC, JSA, sosialisasi kebijakan dan program K3, pelatihan K3, menindaklanjuti temuan K3, dan masih banyak kegiatan lainnya. Selain itu, manajemen juga telah membuat SOP mengenai konsultasi dan komunikasi untuk mengatur mekanisme konsultasi semua masalah K3 yang ada di perusahaan dan memastikan bahwa setiap masalah yang ada, diproses, dan ditindaklanjuti tindakan perbaikan untuk peningkatan berkelanjutan dari SMK3 agar sesuai dengan tujuan dan sasaran yang telah ditentukan.

Vecchio-Sadus (2007) menegaskan bahwa komunikasi keselamatan datang dalam berbagai jenis, misalnya, laporan kejadian, kinerja keselamatan, induksi kerja, dan prosedur dan kebijakan.
Komunikasi dan pelatihan keselamatan dapat mempengaruhi perilaku pekerja dalam melaksanakan pekerjaannya. Neal dan Griffin (2000) mengatakan bahwa perilaku keselamatan merupakan aplikasi dari perilaku tugas yang ada di tempat kerja, yaitu pematuhan dan partisipasi individu pada aktivitas implementasi keselamatan di tempat kerja. Dengan adanya komunikasi dan pelatihan keselamatan yang baik, maka dapat meningkatkan pengetahuan dan pemahaman keselamatan kerja, sehingga pekerja dapat lebih waspada terhadap bahaya yang ada di tempat dan kecelakaan kerja pun dapat dihindari.

\section{Budaya Keselamatan (Safety Culture)}

Berdasarkan hasil survei, observasi, wawancara, FGD, dan studi dokumentasi mengenai budaya k3 di Proyek Citra Tower, didapat hasil sebagai berikut (tabel 6) : 


\section{Jurnal Bidang Ilmu Kesehatan}

Tabel 6. Tingkat Kedewasaan Budaya Keselamatan Di Proyek Citra Tower Kemayoran

\begin{tabular}{lc}
\hline \multicolumn{1}{c}{ Karakteristik } & Nilai \\
\hline Keselamatan sebagai nilai yang diakui dan dipahami & 221,7 \\
Kepemimpinan dalam keselamatan & 222,1 \\
Akuntabilitas keselamatan & 74,3 \\
Keselamatan terintegrasi & 82,9 \\
Keselamatan sebagai penggerak pembelajaran & 70,7 \\
Total & 671 \\
\hline
\end{tabular}

Dari tabel 6 di atas terlihat total nilai yang didapat dari hasil perhitungan pada 5 karakteristik budaya keselamatan adalah 671 artinya bahwa tingkat kedewasaan budaya keselamatan di Proyek Citra Tower Kemayoran termasuk katagori peringkat baik ( $\mathrm{B}=667-833$ ), yaitu kinerja keselamatan sudah sesuai dengan ketentuan yang di syaratkan dan tidak menyebabkan risiko terhadap kepatuhan persyaratan keselamatan.

Berdasarkan hasil perhitungan 5 karakteristik budaya keselamatan, maka dapat digambarkan kondisi kedewasaan budaya keselamatan Di Proyek Citra Tower secara keseluruhan dalam bentuk radar chart di bawah ini.

Gambar 2. Radar Chart Tingkat Karakteristik Budaya Keselamatan Di Proyek Citra Tower Kemayoran

\section{Karakteristik Budaya Keselamatan Proyek Citra Tower, PT Jagat Interindo Jakarta Pusat Tahun 2019}

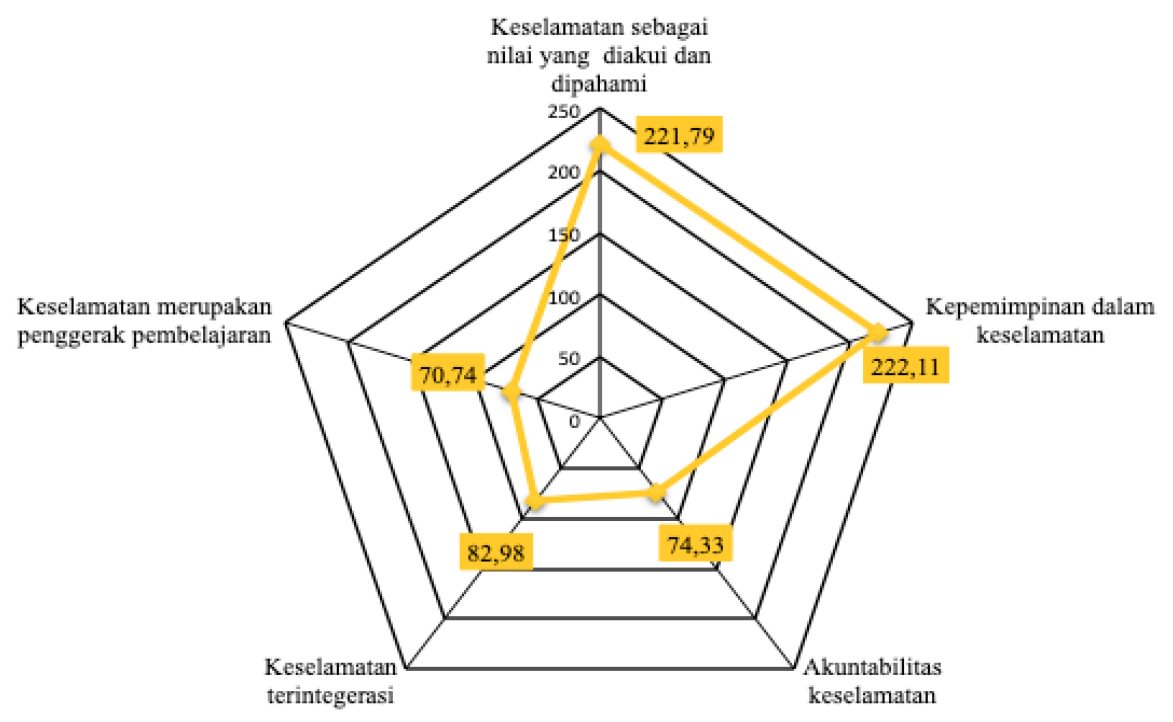


Dari radar chart di atas dapat dilihat karakteristik budaya keselamatan terkuat, yaitu keselamatan sebagai nilai yang diakui dan dipahami mencapai 221,7, dan nilai terlemah pada karakteristik keselamatan merupakan penggerak pembelajaran mencapai 70,7 .

Hasil analisis mengenai budaya keselamatan di proyek Citra Tower mendapatkan total nilai 671 yang berada pada peringkat $B$, artinya proyek Citra Tower Kemayoran memiliki tingkat kedewasaan budaya K3 yang baik. Hal tersebut tergambar dari keselamatan sebagai nilai yang diakui dan dipahami pada proyek Citra Tower Kemayoran, dengan memprioritaskan keselamatan yang ditunjukkan dalam dokumentasi, komunikasi nilai-nilai keselamatan kepada setiap individu melalui sosialisasi, workshop, dan pelatihan K3, serta pengambilan keputusan. Memiliki kebijakan dan komitmen tentang keselamatan, penugasan tanggung jawab, prosedur untuk alokasi sumber daya dan kualifikasi personel yang berurusan dengan keselamatan, dokumen untuk menangani masalah keamanan termasuk masalah karyawan, SOP mengenai setiap kegiatan dan form checklist yang harus dilakukan sebelum melakukan pekerjaan.

$\begin{array}{lll}\text { Menurut PP No. 50/2012 } & \end{array}$ disebutkan bahwa, kebijakan keselamatan dan kesehatan kerja (K3) adalah suatu pernyataan tertulis yang dibuat melalui proses konsultasi antara pengurus dan wakil tenaga kerja yang memuat keseluruhan tujuan perusahaan, komitmen dan tekad melaksanakan K3, kerangka dan program kerja perusahaan yang bersifat umum dan operasional. Kebijkan K3 tersebut oleh manajemen sudah diimplementasikan dengan melakukan visite project manager dan tim HSE untuk melihat kinerja dari para pekerja, serta memantau keselamatan dari setiap kegiatan yang berjalan. Komunikasi yang baik dari para pekerja kepada mandor, supervisor, ataupun tim HSE selalu dilakukan, begitu juga sebaliknya. Hasibuan (2005) mengatakan bahwa komitmen adalah kesanggupan suatu karyawan atau anggota organisasi untuk tetap memelihara sebuah nilai dalam upaya pencapaian tujuan organisasi secara umum. Komitmen organisasi cenderung didefinisikan sebagai suatu perpaduan antara sikap dan perilaku. Komitmen organisasi menyangkut tiga sikap yaitu, rasa mengidentifikasi dengan tujuan organisasi, rasa keterlibatan dengan tugas organisasi, dan rasa kesetiaan kepada organisasi (Ferris dan Aranya, 1983).

Hasil analisis bivariat dilakukan dengan menggunakan metode chi square untuk melihat apakah ada hubungan yang 


\section{Jurnal Bidang IImu Kesehatan}

bermakna secara statistik antara iklim

di Proyek Citra Tower Kemayoran.

keselamatan dengan budaya keselamatan

Tabel 7

Hubungan Antara Iklim Keselamatan Dengan Budaya Keselamatan Di Proyek Citra Tower Kemayoran

\begin{tabular}{|c|c|c|c|c|c|}
\hline \multirow{3}{*}{$\begin{array}{c}\text { Dimensi } \\
\text { Iklim Keselamatan }\end{array}$} & \multicolumn{4}{|c|}{ Budaya Keselamatan } & \multirow{3}{*}{ P Value } \\
\hline & \multicolumn{2}{|c|}{ Baik } & \multicolumn{2}{|c|}{ Kurang Baik } & \\
\hline & $\mathrm{n}(30)$ & $\%(50,8 \%)$ & n (29) & $\%(49,2 \%)$ & \\
\hline \multicolumn{6}{|l|}{ Dimensi 1} \\
\hline Positif & 20 & 52,6 & 18 & 47,4 & \multirow{2}{*}{0,932} \\
\hline Negatif & 10 & 47,6 & 11 & 52,4 & \\
\hline \multicolumn{6}{|l|}{ Dimensi 2} \\
\hline Positif & 20 & 48,8 & 21 & 51,2 & \multirow{2}{*}{0,844} \\
\hline Negatif & 10 & 55,6 & 8 & 44,4 & \\
\hline \multicolumn{6}{|l|}{ Dimensi 3} \\
\hline Positif & 18 & 50,0 & 18 & 50,0 & \multirow{2}{*}{1,000} \\
\hline Negatif & 12 & 52,2 & 11 & 47,8 & \\
\hline \multicolumn{6}{|l|}{ Dimensi 4} \\
\hline Positif & 17 & 48,6 & 18 & 51,4 & \multirow{2}{*}{0,875} \\
\hline Negatif & 13 & 54,2 & 11 & 45,8 & \\
\hline \multicolumn{6}{|l|}{ Dimensi 5} \\
\hline Positif & 21 & 50,0 & 21 & 50,0 & \multirow{2}{*}{1,000} \\
\hline Negatif & 9 & 52,9 & 8 & 47,1 & \\
\hline \multicolumn{6}{|l|}{ Dimensi 6} \\
\hline Positif & 19 & 51,4 & 18 & 48,6 & \multirow{2}{*}{1,000} \\
\hline Negatif & 11 & 50,0 & 11 & 50,0 & \\
\hline \multicolumn{6}{|l|}{ Dimensi 7} \\
\hline Positif & 21 & 48,8 & 22 & 51,2 & \multirow{2}{*}{0,831} \\
\hline Negatif & 9 & 56,3 & 7 & 43,8 & \\
\hline
\end{tabular}

Dari tabel 7 di atas terlihat bahwa 7 dimensi iklim keselamatan tidak berhubungan dengan budaya K3 dengan nilai $p$ value dimensi $1(0,932)$; dimensi 2 $(0,844)$; dimensi 3 (1,000); dimensi 4 $(0,87)$; dimensi 5 (1,000); dimensi 6 $(1,000)$; dan dimensi $7(0,831)$.

Dari hasil uji chi square menunjukkan responden yang mempunyai persepsi positif terhadap dimensi 1 , yaitu sebanyak 20 (52,6\%) responden memiliki kepercayaan, persepsi, dan nilai yang baik terhadap budaya keselamatan, sedangkan sebanyak 11 (52,4\%) yang berpersepsi negatif memiliki kepercayaan, persepsi, dan nilai yang kurang baik terhadap budaya keselamatan dengan $\mathrm{P}$ value yang didapat adalah 0,932 artinya persepsi responden terhadap prioritas keselamatan kerja manajemen, komitmen, dan 
kompetensi tidak memiliki hubungan yang signifikan terhadap budaya keselamatan di Proyek Citra Tower Kemayoran.

Banyaknya proporsi persepsi pekerja yang positif diakibatkan adanya komitmen antara manajemen dan pekerja. Penelitian yang telah dilakukan sebelumnya (Cheyne et al., 1998) menunjukkan bahwa faktor komitmen merupakan salah satu faktor utama budaya keselamatan kerja, tanpa dukungan dari pihak manajemen sangat sulit untuk mencapai keberhasilan dalam menjalankan program keselamatan kerja. Komitmen top manajemen dapat berupa perhatian terhadap keselamatan pekerja, tindakan terhadap bahaya yang mengancam keselamatan kerja, tindakan proaktif yang merupakan pencegahan atau antisipasi terhadap bahaya seperti melengkapi pekerja dengan perlengkapan pelindung keselamatan kerja, pemberian pelatihan keselamatan kerja, pengawasan terhadap keselamatan pekerja maupun tindakan reaktif yang dilakukan bila terjadi kecelakaan kerja, seperti menyediakan obat-obatan, maupun mengantarkan ke rumah sakit (Cheyne et al, 1998).

Hasil observasi menunjukkan manajemen sudah komitmen dan mendukung, serta mewujudkan program K3. Hal tersebut ditunjukkan oleh pihak manajemen dalam terwujudnya nyata kebijakan K3, seperti memberikan APD yang sesuai dengan jenis pekerjaannya; bentuk kegiatan K3 rutin yang diadakan oleh manajemen disambut baik dengan keikutsertaan pekerja di dalam kegiatan K3; pengawasan yang dilakukan oleh petugas safety dilakukan secara rutin, sehingga pekerja merasa keselamatan pekerja diperhatikan oleh pihak manajemen. Safety officer mengatakan melakukan safety induction baik semua pekerja baru yang memasuki area proyek, bagi pekerja yang akan melakukan pekerjaan berisiko tinggi baik dari kontraktor maupun dari subkontraktor, dan bagi tamu yang ingin memasuki area proyek juga diberikan safety induction terlebih dahulu.

Dari hasil uji chi square menunjukkan responden yang mempunyai persepsi positif terhadap dimensi 2, yaitu sebanyak 21 (51,2\%) responden, tetapi memiliki kepercayaan, persepsi, dan nilai yang kurang baik terhadap budaya keselamatan, sedangkan sebanyak 10 $(55,6 \%)$ yang berpersepsi negatif memiliki kepercayaan, persepsi, dan nilai yang baik terhadap budaya keselamatan, dengan $\mathrm{P}$ value yang didapat adalah 0,844 artinya persepsi responden terhadap kewenangan keselamatan kerja dari manajemen tidak memiliki hubungan yang signifikan 
terhadap budaya keselamatan di Proyek Citra Tower Kemayoran.

Di Proyek Citra Tower manajemen mempunyai gaya kepemimpinan yang partisipatif, sehingga berpengaruh kuat terhadap motivasi pekerja, karena manajemen menggerakkan pekerja untuk termotivasi mencapai suatu tujuan dalam menciptakan keselamatan dan kesehatan kerja. Pimpinan yang memiliki karakteristik safety akan menunjukkan kepedulian yang tinggi melalui keterlibatannya secara langsung dalam mendemonstrasikan program K3 yang ditetapkan. Jika pimpinan melihat suatu pekerjaan dilakukan tidak benar, maka beliau akan segera turun mengoreksi kondisi tersebut untuk memperlihatkan komitmen yang tinggi dan meyakinkan pada pekerja bahwa tidak ada toleransi untuk suatu penyimpangan prosedur terkait keselamatan. Hasil penelitian Seo et al. (2004), apabila poin di atas tidak dapat terlaksana, maka tidak akan terbangun persepsi pada seluruh karyawan bahwa lingkungan tempat mereka bekerja memiliki kepedulian terhadap keselamatan kerja yang tinggi.

\section{Eexpectancy-Valency Theory}

menyebutkan bahwa seorang karyawan akan termotivasi untuk berperilaku selamat dalam bekerja apabila mereka percaya bahwa hal itu dapat memberikan hasil atau nilai yang baik (Neal dan Griffin,
2006). Berdasarkan hasil wawancara dengan safety officer, bahwa manajemen berpartisipasi dalam meningkatkan K3, seperti manajemen menjamin pekerja untuk menyebarkan cara kerja yang aman dalam pekerjaan mereka, menjamin pekerja untuk mempunyai kompetensi yang tinggi berhubungan dengan keselamatan, serta menanyakan pendapat pekerja untuk mengambil keputusan tentang risiko yang ada di lapangan.

Salah satu kebijakan K3 yang ada di proyek adalah program K3. Efektifitas dari program K3 yang ada bergantung dari keterlibatan antara komitmen manajemen dengan pekerja. Minner (1998) mengatakan bahwa bertambah atau berkurangnya komitmen bergantung pada dua hal, yaitu sifat pekerja itu sendiri dan karakteristik organisasi kerjanya. Untuk permasalahan yang menyangkut $\mathrm{K} 3$ yang pertama adalah komitmen dan kebijakan. Komitmen perusahaan merupakan elemen inti keberhasilan dari kebijakan K3 dan program $\mathrm{K} 3$, sehingga terjamin tersedianya lingkungan kerja yang aman dan sehat bagi seluruh tenaga kerja.

Dari hasil uji chi square menunjukkan responden yang mempunyai persepsi positif terhadap dimensi 3, yaitu sebanyak 18 (50,0\%) responden, memiliki kepercayaan, persepsi, dan nilai yang porsinya sama besar, yaitu baik dan kurang 


\section{Jurnal Bidang IImu Kesehatan}

baik terhadap budaya keselamatan, sedangkan sebanyak 12 (52,2\%) yang berpersepsi negatif juga memiliki kepercayaan, persepsi, dan nilai yang baik terhadap budaya keselamatan, dengan $\mathrm{P}$ value yang didapat adalah 1,000 artinya persepsi responden terhadap keadilan terhadap keselamatan kerja dari manajemen tidak memiliki hubungan yang signifikan terhadap budaya keselamatan di Proyek Citra Tower Kemayoran.

Aspek keadilan organisasional menjadi sangat penting dalam kehidupan organisasi di proyek, karena apabila keadilan tersebut tidak ada, maka dapat menyebabkan turunnya komitmen, terjadinya kejahatan di lingkungan kerja, dan adanya keinginan untuk melakukan protes. Gibson et al. (2012) mendefinisikan keadilan organisasional sebagai suatu tingkat, seorang individu merasa diperlakukan sama di organisasi tempat dia bekerja. Definisi lain mengatakan bahwa keadilan organisasional adalah persepsi adil dari seseorang terhadap keputusan yang diambil oleh atasannya (Wexley, 1994). Berdasarkan hasil wawancara dengan pekerja bahwa hasil kinerja yang maksimal dikarenakan perusahaan memberikan kenyamanan di area kerja; memberikan jaminan kesehatan, seperti staff diberikan BPJS kesehatan dan BPJS Ketenagakerjaan, untuk pekerja sendiri perusahaan bekerja sama dengan Rumah sakit Mitra Kemayoran yang bila terjadi suatu insiden kecelakaan kerja maupun penyakit akibat kerja maka akan dirujuk ke rumah sakit tersebut dan semua biaya ditanggung oleh perusahaan. Keadilan terhadap keselamatan lainnya ditunjukkan berupa pada saat terjadi kecelakaan kerja manajemen akan mendengarkan dengan seksama semua orang yang terlibat dalam kecelakaan dan memperlakukan pekerja yang terlibat dalam kecelakaan secara adil.

Dari hasil uji chi square menunjukkan responden yang mempunyai persepsi positif terhadap dimensi 4, yaitu sebanyak 18 (51,4\%) responden, tetapi memiliki kepercayaan, persepsi, dan nilai yang kurang baik terhadap budaya keselamatan, sedangkan sebanyak 13 $(54,2 \%)$ yang berpersepsi negatif memiliki kepercayaan, persepsi, dan nilai yang baik terhadap budaya keselamatan, dengan $\mathrm{P}$ value yang didapat adalah 0,875 artinya persepsi responden terhadap komitmen keselamatan kerja dari para pekerja tidak memiliki hubungan yang signifikan terhadap budaya keselamatan di Proyek Citra Tower Kemayoran.

Komitmen pekerja adalah
hubungan antara karyawan dengan
perusahaan yang merupakan orientasi
karyawan pada perusahaan sehingga
bersedia menyumbangkan energinya dan




\section{Jurnal Bidang Ilmu Kesehatan}

mengikatkan diri melalui aktivitas dan keterlibatan dalam perusahaan untuk mencapai tujuan perusahaan. (Oktorita, Rosyid, \& Lestari, 2004). Komitmen pekerja dapat diartikan sebagai penerimaan penuh karyawan atas nilai-nilai dan tujuan perusahaan, sehingga ada keinginan kuat untuk tetap menjadi anggota perusahaan tersebut. Hasil observasi di lapangan banyak pekerja yang mempunyai persepsi posistif terhadap manajemen, sehingga pekerja mempunyai komitmen pada program K3. Komitmen pada pekerja tumbuh didahului dengan adanya niat untuk bekerja dalam suatu organisasi. Karyawan yang mempunyai komitmen tinggi ditandai dengan tingkat kehadiran yang tinggi, keterlibatan terhadap program K3, dan berorientasi pada pencapaian tujuan. Hal ini terlihat dari banyaknya pekerja yang mematuhi peraturan K3 yang ada, seperti menggunakan face shield ketika sedang melakukan welding, menggunakan full body harness ketika melakukan pekerjaan di atas ketinggian > 1,8 meter, menjaga kerapihan dan kebersihan area sekitar proyek.

Dari hasil uji chi square menunjukkan responden yang mempunyai persepsi positif terhadap dimensi 5, yaitu sebanyak 21 (50,0\%) responden, memiliki kepercayaan, persepsi, dan nilai yang porsinya sama besar, yaitu baik dan kurang baik terhadap budaya keselamatan, sedangkan sebanyak 9 (52,9\%) yang berpersepsi negatif juga memiliki kepercayaan, persepsi, dan nilai yang baik terhadap budaya keselamatan, dengan $\mathrm{P}$ value yang didapat adalah 1,000 artinya persepsi responden terhadap prioritas keselamatan kerja dari pekerja dan sikap tidak mau ambil risiko keselamatan kerja tidak memiliki hubungan yang signifikan terhadap budaya keselamatan di Proyek Citra Tower Kemayoran.

Berdasarkan hasil wawancara pada pekerja, bahwa pekerja yang memiliki persepsi negatif masih menganggap risiko yang ada di lapangan masih dapat toleransi, menganggap kecelakaan yang ringan adalah suatu kecelakaan yang wajar, serta tidak keberatan menerima risiko yang ada di lapangan asal tidak menimbulkan kecelakaan. Menurut Robbins (2003), persepsi yang dimiliki dapat mempengaruhi tindakan seseorang, jika teori tersebut dikaitkan dengan hasil penelitian dapat dikatakan bahwa mayoritas para pekerja konstruksi menyadari akan risiko yang akan mereka hadapi dan hal itu mempengaruhi perilaku mereka dalam rangka melindungi diri dari risiko dengan patuh menggunakan alat pelindung diri yang telah disediakan sesuai dengan pekerjaan mereka. Neal dan Griffin 
(2004) menyatakan bahwa iklim keselamatan memiliki pengaruh langsung terhadap peningkatan perilaku keselamatan dan penurunan angka kecelakaan kerja. Salah satu komponen dari perilaku keselamatan adalah kepatuhan keselamatan. Kepatuhan terhadap peraturan keselamatan akan semakin meningkat apabila karyawan mempunyai persepsi bahwa iklim keselamatan kerja yang dirasakan sangat mendukung, sehingga semakin positif persepsi pekerja terhadap praktik keselamatan manajemen, semakin tinggi kepatuhan pekerja terhadap peraturan keselamatan.

Dari hasil uji chi square menunjukkan responden yang mempunyai persepsi positif terhadap dimensi 6, yaitu sebanyak 19 (51,4\%) responden memiliki kepercayaan, persepsi, dan nilai yang baik terhadap budaya keselamatan, sedangkan sebanyak 11 (50,0\%) yang berpersepsi negatif memiliki kepercayaan, persepsi, dan nilai yang porsinya sama besar, yaitu baik dan kurang baik terhadap budaya keselamatan dengan $\mathrm{P}$ value yang didapat adalah 1,000 artinya persepsi responden terhadap komunikasi dan pelatihan keselamatan kerja tidak memiliki hubungan yang signifikan terhadap budaya keselamatan di Proyek Citra Tower Kemayoran.
Hal tersebut terjadi karena program K3 dapat berfungsi dan efektif, program K3 yang ada dapat terkomunikasikan kepada seluruh lapisan individu yang terlibat pada proyek konstruksi, serta mempertimbangkan pendapat pekerja mengenai keselamatan, manajemen dan pekerja memiliki kepercayaan terhadap kemampuan satu sama lain untuk menjamin keselamatan. Hasil wawancara pekerja mengatakan bahwa, tidak patuh terhadap peraturan K3 akan dikenakan sanksi yang diberikan. Hal tersebut mempengaruhi pekerja untuk patuh pada peraturan K3. Pekerja juga memberikan saran kepada manajemen yang terkait dengan keselamatan, komunikasi dua arah ini tercipta demi kenyamanan dan keamanan pekerja di lingkungan kerja. Manajemen pun mempertimbangkan saran dari pekerja terkait dengan keselamatan.

Neal \& Griffin (2002), berpendapat bahwa hanya ada tiga faktor yang menentukan perbedaan individu dalam performansi, yaitu pengetahuan, kemampuan, dan motivasi. Jika seseorang tidak memiliki cukup motivasi untuk patuh terhadap peraturan keselamatan atau terlibat dalam aktivitas keselamatan, maka dia tidak akan memilih untuk melakukan tindakan aman. Selain itu, jika seseorang tidak memiliki pengetahuan dan 


\section{Jurnal Bidang IImu Kesehatan}

kemampuan yang cukup untuk patuh dengan peraturan keselamatan atau terlibat dalam aktivitas keselamatan, maka dia tidak akan mampu melakukan tindakan aman. Hal itu juga didukung dengan komunikasi dan pelatihan keselamatan yang dilakukan selama proyek berlangsung semua pekerja dilibatkan dalam komunikasi dan pelatihan keselamatan sehingga pengetahuan pekerja semakin bertambah. Peningkatan kualitas sumber daya manusia merupakan langkah penting dalam meningkatkan kemampuan kerja karyawan. Untuk meningkatkan sumber daya manusia diperlukan sebuah pelatihan. Pelatihan keselamatan dan kesehatan kerja merupakan pelatihan yang diselenggarakan dan diarahkan untuk membekali, meningkatkan, dan mengembangkan kemampuan, produktivitas, dan kesejahteraan tenaga kerja. Kebutuhan pelatihan keselamatan dan kesehatan kerja antara satu perusahaan dengan perusahaan lain berbeda sesuai sifat bahaya, skala kegiatan dan kondisi pekerja (Ramli, 2010).

Pelatihan K3 sangat penting mengingat kebanyakan kecelakaan terjadi pada pekerja yang belum terbiasa bekerja secara selamat. Penyebabnya adalah ketidaktahuan tentang bahaya atau cara mencegahnya meskipun tahu tentang adanya suatu risiko (Santoso, 2004). Hasil wawancara dengan pekerja mengatakan bahwa manajemen memberikan pelatihan K3 kepada pekerja, seperti pelatihan basic safety, pelatihan bekerja diketinggian, pelatihan penggunaan full body harness, pengenalan safety sign yang ada di proyek, pelatihan emergency. Hal itu membuat pekerja merasa di perhatikan terhadap keselamatan kerja, sehingga pekerja tidak ada alasan untuk tidak mematuhi aturan keselamatan yang ada.

Dari hasil uji chi square menunjukkan responden yang mempunyai persepsi positif terhadap dimensi 7, yaitu sebanyak 22 (51,2\%) responden, tetapi memiliki kepercayaan, persepsi, dan nilai yang kurang baik terhadap budaya keselamatan, sedangkan sebanyak 9 $(56,3 \%)$ yang berpersepsi negatif memiliki kepercayaan, persepsi, dan nilai yang baik terhadap budaya keselamatan, dengan $\mathrm{P}$ value yang didapat adalah 0,831 artinya persepsi responden terhadap kepercayaan pekerja terhadap sistem keselamatan kerja tidak memiliki hubungan yang signifikan terhadap budaya keselamatan di Proyek Citra Tower Kemayoran.

Persepsi pekerja terhadap kepercayaan sistem keselamatan kerja masih banyak yang memiliki persepsi positif. Kepercayaan pekerja terhadap manajemen tumbuh apabila manajemen mempunyai komitmen dan kompetensi 


\section{Jurnal Bidang IImu Kesehatan}

terhadap K3 serta memprioritaskan keselamatan. Manajemen harus memiliki perencanaan awal dan tujuan yang jelas terhadap program K3, sehingga pekerja secara langsung dan tidak langsung ikut andil dalam terbentuknya perilaku keselamatan melalui iklim keselamatan. Dalam penelitiannya Hale (2000) mengatakan, bahwa ketidakpercayaan terhadap sistem kontrol risiko, merupakan salah satu budaya yang kurang baik untuk menyampaikan kepercayaan sistem keselamatan kerja pada pekerja diperlukan pendelegasian program K3. Sehingga pekerja mempunyai kontribusi terhadap program K3 yang ada, dan manajemen melakukan penilaian dan menghargai kontribusi pekerja.

Baiknya persepsi tersebut menurut safety coordinator bahwa manajemen sudah mempunyai kebijakan K3 yang mengatur K3 di proyek. Kebijakan K3 merupakan perwujudan dari komitmen pucuk pimpinan yang memuat visi dan tujuan organisasi, komitmen dan tekad untuk melaksanakan keselamatan dan kesehatan kerja, kerangka dan program kerja (Ramli, 2010). Menurut Modjo (2007) manfaat penerapan program K3 salah satunya pengurangan absentisme, perusahaan yang serius menerapkan program ini akan dapat menekan angka risiko kecelakaan kerja, sehingga karyawan yang tidak masuk alasan cedera dan sakit akan semakin berkurang.

\section{SIMPULAN}

1. Tingkat persepsi manajemen dan pekerja terhadap iklim keselamatan di Proyek Citra Tower Kemayoran adalah termasuk katagori cukup baik, dengan nilai 2,02-3,07.

2. Tingkat kedewasaan budaya keselamatan di Proyek Citra Tower Kemayoran adalah termasuk katagori baik dengan nilai 671 .

3. Tujuh dimensi iklim keselamatan tidak berhubungan dengan budaya K3 dengan nilai p value dimensi $1(0,932)$; dimensi 2 (0,844); dimensi 3 (1,000); dimensi $4(0,87)$; dimensi 5 (1,000); dimensi 6 (1,000); dan dimensi 7 $(0,831)$.

\section{DAFTAR PUSTAKA}

Amponsah-Tawaih, K., \& Adu, M. A., 2016, Work Pressure and Safety Behaviors among Health Workers in Ghana: The Moderating Role of Management Commitment to Safety. Safety and Health at Work. 340- 346. doi:10.1016/j.shaw.2016.05.001

Christina, Wieke Yuni, 2012, Pengaruh Budaya Keselamatan dan Kesehatan Kerja (K3) Terhadap 
Kinerja Proyek Konstruksi, Jurnal Rekayasa Sipil, Volume 6, No. 1.

Cooper, MD., 2000, Towards a model of safety culture, Safety Science. vol.36. pp111-136

Cigularov, Konstantin P., Chen, Peter Y., John Rosecrance, 2010, The Effect Of Error Management Climate And Safety Communication On Safety. Accident Analysis and Prevention 45, 745-758.

Cheyne, A., Sue, C., Oliver, A., and Tomas, J.M., 1998, Modeling Safety Climate in the Prediction of Levels of Safety Activity, Work \& Stress, 12, 3, 255271.

Dhakiri, Hanif , 2018, Menaker: Sepanjang 2017, ada 1.877 kecelakaan tenaga konstruksi,

https.kontan.co.id.menakersepanjang-2017-ada-1877-kecelakaantenaga-konstruksi. Diakses : Rabu, 21 Maret 2018 / 07:56 WIB.

Flin, R., 2000, Measuring Safety Culture in Health Care: A case of Accurate Diagnosis, International Journal for Quality in Health Care, Diakses : 22 Juli 2014.

Ferris, K. dan Aranya, N., 1983, A Com Parison of Two Organizational Commitment Scales. Personnel Psychology, 36, 87-98.
Feinstein, Andrew Hale, Willianm Harrah, 2000, A Study of Relationship Between Job Satisfaction and Organization Commitment Among Restaurant Employee (online). www.emeraldinsight.com.

Guldenmund, F.W., 2000, Definitions of Safety culture, Safety Science.

Glendon. A.L. dan Litherland, D.K, 2001, Safety Climate Factor. Group Differences and Safety Behaviour in Road Construction, Journal of Safety Sciences 157-188.

Gershon, R. M., Karkashian, C. D., et.al, 2000, Hospital Safety Climate and its Relationship with safe work practices and workplace exposure incidents, American Journal of Infection Control, 28, 211-221.

Gibson, James L., et.al., 2012, Organization: Bbehaviour, Structure, Processes. $14^{\text {th }}$ Edition. New York: McGrawHill Companies, Inc

Huang, Y., Robertson M.M., Lee, J., Rineer, J., Murphy, L.A., Garabet, A., Dainoff,M.J., 2014,

\section{Supervisory Interpretation ofSaf} ety Climate Versus Employee Safety Climate Perception: Association with SafetyBehavior and Outcomes for LoneWorkers, Journal of Transportation Research Part F, Vol. 26 , 348-360. 
Jurnal Bidang Ilmu Kesehatan

Hasibuan, Malayu S.P., 2005, Manajemen Sumber Daya Manusia, Edisi Revisi. Bumi Aksara, Jakarta.

International Atomic Energy Agency (IAEA), 1991, Safety Culture (International Safety Advisory

Group, Safety-Series 75- INSAG-4), International Atomic Energy Agency, Vienna.

2008, SCART Guideline

Reference Report for IAEA Safety Culture Assessment Review Team, International Atomic Energy Agency, Vienna.

Jebb, S., 2015, Reducing Workplace Safety Incident: Bridging The Gap Between Safety Culture Theory And Practice. Dissertation. Queensland University Of Technology

Kines, Pete., Lappalainen, Jorma., Mikkelsen, K.L., Olsen, E., Pousette, Andersen., Tharaldsen, J., Tomasson, Kristinn., Torner Marianne, 2011, Nordic Safety Climate Questionnaire (NOSACQ50): A New Tool for Diagnosing Occupational Safety Climate.

International Journal of Industrial Ergonomics, 41, 634-646.

Mola, Thomas, 2018, 6 Penyebab Kecelakaan Konstruksi, Gapensi: Harusnya Bisa Dihindari,https://www.bisnis.compenyebab-kecelakaan-konstruksi-gapensi harusnya-bisa-dihindari, Diakses : 06 Februari 2018 08:44 WIB

Modjo, Robiana, 2007, Modul Promosi Kesehatan dan Keselamatan Kerja. http://www.staff.ui.ac.id/internal/ 132096019/modul-promosi-kesehatandankeselamatan- kerja.pdf.

Neal, A., danGriffin, M. A., Hart, P.M. ,2000, The Impact Of Organizational Climate On Safety Climate And Individual Behavior, Safety Science Vol 34, 99-109. 2000, Perceptions of safety at work: A framework for linking safety climate to safety performance, knowledge, and motivation. Journal of Occupational Health Psychology 5 : 347 358 2002. Safety Climate and Safety Behaviour. Australian Journal of Management 27 (special issues), 6773. Diakses 14 Januari 2016; http://www.researchgate.net/publication/ 27478788 2004, Safety Climate and Safety at Work, The Psychology of Workplace Safety (Eds. Barling, J, \& Michael R.F.). Washington: American Psychology Association. , 2006, A Study of The Lagged Relationship Among Safety Climate, Safety Motivation, Safety Behavior, and Accidents at The Individual and Group Levels. Journal of Applied Psychology. 
91(4), 946-953. doi:10.1037/00219010.91.4.946

Oktorita. B., Rosyid, dan Lestari, 2004, Hubungan Antara Sikap Terhadap Penerapan Program K3 dengan Komitmen Karyawan Pada Perusahaan. Jurnal. Yogyakarta : Fakultas Psikologi Universitas Gadjah Mada.

Prins, David Saut, 2018, Angka Kecelakaan Kerja RI Meningkat ke 123 Ribu Kasus di 2017,

https://finance.detik.com,angka-

kecelakaan-kerja-ri-meningkat-ke-123-ribu

kasus-di-2017, Diakses : Selasa, 06

Feb 2018 16:14 WIB.

Pecquet, C.F., 2013, Measuring Safety Climate As An Indicator Of Effective Safety And Health Programs In The Construction Industry. Dissertation. The Sc hool of Human

Resource Education and Workforce Devel opment.

Peraturan Pemerintah No.50 Tahun 2012 tentang Sistem Manajemen Kesehatan dan Keselamatan Kerja.

Rafidah, Abdul, R.,dkk tentang "Impact of Safety Communication on Safety Commtiment with LeaderMember Exchange Quality as A Moderating Factor: A Conceptual Frame Work" Reason, J., 1997, Managing the Risks of Organizational Accidents, Ashgate Publishing Limited, England.
Robbin, Stephen P., 2003, Perilaku Organisasi, Jakarta: PT. Indeks Kelompok Gramedia, Jakarta.

Ramli, Soehatman, 2010, Sistem Manajemen Keselamatan \& Kesehatan Kerja OHSAS 18001. Jakarta : Dian Rakyat.

Supriyadi, Agung, 2018, 14 Kecelakaan Konstruksi 2017-1018, https://katigaku.top.14-kecelakaankonstruksi-2017-2018menghentikan-sementara-proyek, Diakses : 26/02/2018.

Somad, Ismet, 2013, Teknik Efektif Dalam Membudayakan Keselamatan dan Kesehatan Kerja, Jakarta, Dian Rakyat.

Seo, D. C., Torabi, M. R., Blair, E. H., Ellis, N. T., 2004, A Cross-Validation of Safety Climate Scale Using Confirmatory Factor Analytic Approach. Journal of Safety Research, 35, 427-445

Santoso, G., 2004, Manajemen Keselamatan dan Kesehatan Kerja. Prestasi Pustaka, Jakarta

Taqwa, Khoiruz Zadit, 2017, Hubungan Antara Safety Climate Dengan Safety Behavior Pada Karyawan Departemen Produksi PT Pura Barutama Unit Offset, Kudus, Jurusan 
Psikologi, Fakultas IImu Pendidikan,

Universitas Negeri Semarang.

The Reach Group, Ime J., 1984, Soyb ean oil refining, Available from: www.asae urope.org/p d df/1.pdf, diakses Mei 2014.

Vecchio-sadus, A. M., 2007, Enhancing Safety Culture Through Effective Communication, 1-9.

Wiegman, Douglas A., et al, 2002, A Sythesis of Safety Culture and Safety Climate Research. Aviation Research
Lab Institute of Aviation, University of Illinois.

Widianto, Satrio, 2019, Kecelakaan Kerja 2018 Mencapai 173.105 Kasus, www.pikiranrakyat.co-kecelakaan-kerja2018-mencapai-173105-kasus, Diakses 15 Januari 2019, 20:07. Wexley, K. N., and Yukl, G.A., 1994, Managemen dan Organisasi. Jakarta: PPM 